\title{
REFLECTING ON THE USE OF DESIGN METHODOLOGY IN ENGINEERING DESIGN EDUCATION
}

\author{
S. Li*, G. Gress, P. Ziadé \\ Schulich School of Engineering, University of Calgary \\ *Corresponding Author E-mail Address: simoli@ucalgary.ca
}

\begin{abstract}
In the teaching of engineering design, it may be common to use design methodology (DM), as documented in several textbooks, in the course delivery. However, considerable drawbacks could be observed in our case when DM is taken as the major guidance for a capstone design course. We argue that DM tends to prescribe some context-free methods and procedures, which cannot be easily applied by students to their capstone design projects. At the same time, we observe that students need support to characterize a design problem, integrate technical knowledge in design activities and verify design ideas. These aspects require analytical and critical thinking, where DM may not be particularly helpful for students. In the five-year journey of deemphasizing DM in a capstone design course, we have explored and examined various pedagogical approaches such as online modules, design labs and peer evaluations. Without the teaching of DM, the pedagogical strategy needs to be carefully planned to deliver specific learning in engineering design.
\end{abstract}

Keywords: Capstone design projects: design methodology: pedagogy in practice.

\section{INTRODUCTION}

The intent of this paper is to reflect on the challenges of using design methodology in a capstone design course over a five-year period. By "design methodology", we refer to a list of methods that are used to support various activities at different design stages. Arguably, these design methods constitute the main contents of many engineering design textbooks such as [4], [5], [10], and [11].

Initially, design methodology (DM) was considered a formal approach for students to address design problems systematically. Thus, in a two-semester capstone course (with $120+$ students), we initially taught DM as a technical subject (i.e., adopted a design textbook and delivered three 1-hour lectures per week). While the students worked on their capstone design projects (sponsored by industry, professors or non-profit organizations), we expected them to apply DM for solving their design problems.
While it may sound logical, this initial approach simply did not work out to our expectations. One important observation is that the final quality of the design solution is not quite related to the execution of DM (e.g., a good design result could have less to do with the use of DM). With frustrations, we know that we need to make changes. Without understanding the core issues then, we could easily "lay blames" to students (e.g., they did not appreciate the importance of DM) and to ourselves (e.g., we needed to improve the quality of lectures). While keeping DM as our teaching philosophy, we have modified the lecture delivery (e.g., more design examples and interactive activities) and the assessments (e.g., multiplechoice questions and self-reflections) to make DM more relevant to capstone design projects.

However, after some years of changes and observations, we come to a viewpoint that DM is not suitable as a major guide for teaching our capstone design course. In this paper, we first analyze in Section 2 why DM may not be suitable for teaching capstone courses based on our observations in practice. By recognizing "capstone" as a special kind of design process (i.e., a fixed 8-month process without an organizational hierarchy), we suggest a capstone design process in Section 3 that we currently use to guide our students in a capstone design course. In Section 4, we review our pedagogical approaches with comments on their pros and cons in practice. Section 5 will provide closing remarks.

\section{CHARACTERISTICS OF DM}

One origin of DM can be traced back to the German tradition from the 1920s [12]. The intent of this development is to treat engineering design as a formal discipline so that people can learn the relevant knowledge and skills systematically. We consider that the advocation of DM has stimulated the field of design theory, which tries to explore the fundamental nature of design [3]. Overall, one academic aim of design theory and methodology is to treat "design" as a subject similar to natural sciences. As a result, it is not difficult to find that DM shares some characteristics of natural science subjects. In this section, 
we discuss three characteristics of DM, and how they may influence the teaching of a capstone design course.

\subsection{Deductive Reasoning}

DM quite relies on deductive reasoning, where general principles (analogous to scientific laws) are used to analyze and interpret information. For example, in the phase of concept generation, the method "morphological chart" is based on the principle of "form-follows-function" [6, p. 3]. It advocates that designers should first think of the purposes or functions of the design and use such information to explore different design solutions. This method also supports the general thought about creativity that more design ideas are better.

In the teaching of the morphological chart, we find that "function" is not an easy concept for students to understand and use at the beginning of the project (e.g., easily confused with specifications and performance metrics). In contrast, when they have finalized their design idea, they can identify more clearly the major functions associated with their design. In this observation, we notice that such functional reasoning for concept generation requires certain experience by designers (e.g., designed similar devices before). In many cases, though, students do not have an adequate level of experience to use the technique of functional reasoning effectively.

Further, is "form-follows-function" a rule or just a reference point for concept generation? A similar question can also be asked of other design principles and methods (e.g., quality function deployment for benchmarking and decision matrix for concept selection). In our view, these principles and methods can be good but we need some judgement on their applicability to specific design projects (e.g., nature of design problems and experience of designers). This judgement in general is difficult for students. Also, the methods and principles are arguably far from "the rules" for design problems in a scientific sense. However, DM has somewhat promoted this kind of deductive reasoning, which may discourage students from developing their own design thinking suitable for the design problem and their levels of design experience.

\subsection{Independence of Design Problems}

As an illustration, the Bernoulli equation in fluid mechanics can be used for designing a pipe system and also an airfoil. That is, this equation can support different design activities, but design activities will not affect the contents of this equation. Then, we can say that the Bernoulli equation is independent of design problems. Similarly, the researchers of DM intend to develop the design methods that can be applied for many kinds of problems, but the solution process of these problems will not alter the design methods.

In the context of capstone design courses, this kind of independence has caused certain issues because the design problems received in a capstone course are quite diverse.
They can be a water filtering system for remote areas, an energy-recovery system for a refinery process or a modification of a wheelchair for better mobility. In our experience, students need guidance that is more specific than what DM offers. For example, instead of "brainstorming" a water filtering system, more initial efforts should be directed to researching existing waterfiltering techniques and comparing their pros and cons. By teaching DM, students can easily shift their focus to the brainstorming exercise because it is what DM tends to emphasize. In other words, the issue of "problem independence" of DM is that it tends to suggest design methods that are simply too general. Students cannot easily get practical guidance by learning DM.

\subsection{Independence of a Designer's Experience}

In the teaching of science subjects, we are sensitive to the prior knowledge of students before introducing a new principle. For example, before teaching the Bernoulli equation, students should know some physical concepts such as pressure and potential energy. However, it seems that DM does not specify clearly the learning ladder of engineering design. Then, two issues can be encountered when teaching DM in a capstone course.

Firstly, how do we know whether a design method is too advanced for our students to understand? For example, many students find the notion of "functions" difficult. We think it is likely related to their design experience. If a student has not visualized and experienced the functioning of a particular design before, identifying the functions of this design can be too abstract to them.

Secondly, beyond understanding, how much experience should a student have in order to "appreciate" the relevance of a design method in practice? For example, DM suggests the use of decision matrix to select "the best" design concept from a set of multiple ideas. In our observation, it is common that a student team has already selected their preferred design idea. Then, they work backwards using a decision matrix to "justify" their decision. Notably, the student team here can "understand" decision matrix. Yet, they only use it to satisfy the requirement of DM in a course rather than for authentic guidance. In real-life practice, decision matrix is recognized a useful tool. Probably because students have not observed and experienced controversial or critical decisions in a workplace, they cannot easily appreciate the clarity of decision matrix for supporting a less-biased decision in a group setting.

In sum, we think that a designer's experience is crucial towards what they can learn from a design process. However, DM does not address too much the relevance of such experience in their methodological framework.

\subsection{Closing Remarks}

To clarify, we are not completely rejecting DM in engineering design education, as we try to put our focus to the context of capstone design projects. On the contrary, 
we think DM can help instructors to develop their own framework to teach design. However, if we use DM as the major guidance to teach a capstone design course, we find students mostly cannot get the benefits from it. At the same time, we find that students do need guidance in their design work such as how to analyze a design problem effectively, how to integrate scientific knowledge in a design project, and how to verify a design idea. In the next section we will discuss our approach in teaching a capstone design course.

\section{CAPSTONE DESIGN PROCESS: A SUGGESTION}

Given the above criticisms of DM, should we then leave capstone as a pure project course? That is, a capstone instructor mainly takes care of the course logistics (e.g., assignment of projects and control of deadlines), while students execute the design projects per their own understanding, along with advisory and prototyping supports from academic and technical staff. In our view, a "pure project" approach is not desirable since it lacks our own vision, as educators, about what we want our students to learn in a course. Also, there are some common design skills that should be learned in a capstone course.

First, we agree with the DM's view that engineering design is a process, where we classify a capstone design process with three stages: (1) conceptual design, (2) design development, and (3) design verification. As a point of departure, we do not advocate specific "methods" that must be used in a design project. Instead, we explain our expectations for each stage, typical design tasks and practical notions to support critical thinking in design. Here, the teaching philosophy is to first set up some common standard for all capstone projects. Then, we allow flexibility for students to consider what design tasks (or methods) are deemed eligible for their design projects. This section will further elaborate the contents and our views of these three stages.

\subsection{Conceptual Design}

The importance of conceptual design has been emphasized in DM since early design decisions can impact significantly the downstream manufacturing cost $[10$, p. 5]. Also, it is more economical to make design changes during the conceptual design stage than making similar changes at the later design stage [4, p. 54]. Due to its significance, DM researchers and design educators have suggested many tools to support conceptual design such as quality function deployment (QFD) for engineering specifications [10, chapter 6], the morphological chart for concept generation [4, chapter 6.6] and the pairwise comparison chart for ranking objectives [5, chapter 4.3].

As discussed before, the applicability of these tools to specific projects is situational. For example, QFD may not be suitable for a project with less concern of marketing, and QFD is not a simple tool for many students. Thus, we do not instruct the application of specific conceptual design tools. Instead, we mainly check on some essential information below that should be applicable for various kinds of design projects:

- Problem statement. We assess the effectiveness of the problem statement for a technical audience who is not familiar with the project (e.g., instructor) to know the essence of the design problem. Besides communication, it is also about project management concerning the identification of expected deliverables of the project (i.e., the project's scope).

- Performance metrics. While we still discuss the notions of requirements and specifications, we closely check with the team on their definition of "performance metrics" to objectively assess the merits of their own design. One type of check is the appropriateness of the performance metrics for the project (e.g., should weight be a performance metric for the gearbox design of a mini Baja?).

- Design solution. We assess the feasibility of a preliminary design solution (or a design concept) proposed by the team. In the capstone's context, feasibility is not just about technical feasibility but also the existing support of prototyping (e.g., resources from the maker space) as well as the readiness for design testing.

To further support students to contribute to their design projects reasonably, we have listed some typical design tasks for each stage, as shown in Table 1. From this list, we confirm with our students that some tangible contributions are acknowledged as good and meaningful design efforts. Then, students can allocate their design efforts collaboratively as a team.

In our observation, students need help in conceptual design, and their issues cannot be resolved by simply applying certain design methods. For example, students can easily get confused with some terms such as specification vs. performance metrics. Also, quantifying the details can be challenging for them, from defining the notion of "light weight" (e.g., what weight value is considered "light weight" for a gearbox) to specifying the measures for "user-friendliness." Also, some design attributes can be easily misused such as robustness vs. reliability. Sometimes, students even confuse the meaning of "design solution," where we need to explain the level of details that are necessary to fairly describe a design solution specific to the project. This kind of guidance, in the end, cannot be effectively delivered in lectures. Instead, we need to meet individual teams to facilitate relevant discussions to the context of their projects.

Thus far, the description of conceptual design may sound trivial. However, upon closer examination of the DM's perspective, we have actually "de-emphasized" conceptual design by not explicitly requiring multiple design solutions and concept selection. To clarify, we welcome a design project that demonstrates systematic 
treatments of concept generation and selection. The challenge remains that not all projects can easily go through such systematic treatments. For example, for a project involving a lot of industry codes and standards, we would encourage students to study this background rather than practicing the morphological chart.

By "de-emphasizing" conceptual design, we ask our students to come up with a reasonable (not necessarily "the best") design solution that can be further developed in the course. Since students need to develop and verify their own design, we ask for the preliminary design idea no later than the end of November (if the project starts in Sept). Arguably, by the typical design experience of students, they tend to learn more from concrete activities (e.g., design testing) than from "abstract" activities (e.g., exploring possible solutions). Extending the conceptual design period is not particularly beneficial for students. Notably, this viewpoint about the design process is specific to the capstone design situation (i.e., we do not intend to generalize this viewpoint for all kinds of design projects).

Table 1: Typical design tasks at three design stages.

\begin{tabular}{|l|l|}
\hline Design stages & Design tasks \\
design & $\begin{array}{l}\text { Background research } \\
\text { - Find and compare existing solutions } \\
\text { - Learn relevant scientific knowledge } \\
\text { - Study relevant codes and standards } \\
\text { Information gathering \& development } \\
\text { - Identify requirements / constraints } \\
\text { - Develop spec's and perform. metrics } \\
\text { Design ideas and concepts } \\
\text { - Compare different design ideas } \\
\text { - Explain how the design idea works }\end{array}$ \\
\hline $\begin{array}{l}\text { Design } \\
\text { development }\end{array}$ & $\begin{array}{l}\text { Decision problem } \\
\text { - Identify options and selection criteria } \\
\text { Analysis problem } \\
\text { - Formulate the analytical models } \\
\text { - Discuss analysis results } \\
\text { Develop design details } \\
\text { - Develop design representations } \\
\text { - Develop bill of materials }\end{array}$ \\
\hline Design & $\begin{array}{l}\text { Make prototypes (or simulation models) } \\
\text { - Plan the progress of prototyping } \\
\text { - Consider other observable evidence } \\
\text { Develop test plans } \\
\text { - Plan different control factors } \\
\text { - Relate results with perform. metrics } \\
\text { Execute test plans } \\
\text { - Analyze test results } \\
\text { - Recommend design revisions }\end{array}$ \\
\hline
\end{tabular}

\subsection{Design Development}

Design development is about developing the details of the final design, and it can refer to the embodiment and detail design in some textbooks [8, chapters $7 \& 8]$ and $[4$, chapters $8 \& 9$ ]. This stage can cover a wide range of topics such as design for manufacturing, design for sustainability, human factors, robust design and optimization. In fact, some of these topics can be taught as regular technical subjects (e.g., a cost-and-benefit analysis for a new sustainable design idea).

It becomes challenging to "teach" these topics in a capstone design course because students are working on different projects. It is not easy to find a single topic that is useful for all capstone projects (even in a single engineering discipline). For example, we may think "design for manufacturing" is common in mechanical engineering since their capstone projects are often required to build prototypes. In this topic, we may explain the reasons of using standardized parts for lower purchasing and maintenance costs. In our observation, students could learn these reasons in their heads but did not go to the faculty's machine shop to check what standard parts and machines are available for their prototyping. In addition, the principles of "design for manufacturing" are mainly for production, where prototyping is different in view of volume (i.e., likely only one is made) and purpose (i.e., design checking vs. product selling).

As a result, our capstone course does not intend to instruct any new knowledge about engineering design for the whole class. Instead, we explain three types of design tasks, listed in Table 1, for design development. In our practice, we first ask students to discuss the tasks that they aim to perform. Accordingly, we provide feedback to confirm their strengths and correct weaknesses. This approach is like "learning-by-doing" that students first experience the design problem before our feedback.

In our observation, students need guidance to understand the difference between analysis and decision problems. Also, they need confirmation about the essence of decision making that is not about finding the "optimal winner." Instead, a good decision process should inform the implied trade-off and highlight the judgement behind a decision. In addition, one common issue is that students tend to select and perform the tasks based on what they know rather than what the project needs. For example, students are comfortable performing finite element analysis (FEA) since they have learned it in a previous course. As a result, FEA is commonly found in capstone projects, even on some components that are almost impossible to break in practice. In this context, we need to guide the students to perform engineering analysis that should be significant to some design details. 


\subsection{Design Verification}

Compared to conceptual design and design development, it seems that design verification receives less attention in engineering design textbooks. To clarify, certain textbooks did describe prototyping processes [11, chapter 14] and [5, chapter 10]. However, one perception remains that the completion of design details is the end point of a design project. We argue that a capstone design project should also include design verification, where the design team should provide "observable evidence" concerning the properties and merits of the design. For example, beyond completing a functional prototype, the design team should conduct some testing to verify whether and how well the design achieves the intended goals and specifications.

We choose the term "observable evidence" in order to address some cases where a physical prototype is not feasible. For example, some capstone design deliverable can be a HVAC (heating, ventilation and air conditioning) system, where the physical implementation is beyond the project's scope. Then, after completing the design schematics as the final design, the team can verify if the final design satisfies some goals (e.g., energy consumption) via simulation. Such verification, ideally, should be observable and quantifiable so that some third party can examine the results.

"Design verification" in a capstone project was simply a general idea that students should test their own designs. Further in our observation, without the emphasis of design verification, students tend to treat prototypes as the end point of the capstone project and trivialize the design process. For example, evaluators (e.g., academics and industry) can have different opinions about the final design visualized in a prototype, re-enforcing a perception that design is subjective. If that is the case, students would wonder why we need to be thoughtful in the design process (as the final design will be subject to different opinions anyway). By having design verification, it is then not about how others comment on their designs. Instead, students need to step in to provide such information. In turn, they can be more serious and engaged with their own designs.

Though engineering students should have learned a lot of sciences, we find that sometimes they do not even know what verification means in practice. Thus, we first explain the notion of "observable evidence." Then, we clarify different types of prototypes, which should be developed per the scope of the project and the intents of verification. Also, we briefly explain the concepts of experiments, control factors and statistical analysis. As these contents can be technically intensive, we mainly provide an overview for their awareness. When meeting with individual teams, we provide guidance on what specific tasks the team can work on to perform design verification.

As an additional benefit, the focus on design verification has also promoted the participation of faculty members in capstone projects. By training, we would say that most engineering faculty members are scientists. In science, experimentation and verification are very important practices. By analogy, any design idea is like a hypothesis in science. Then, design verification can be a good practice to promote a scientific mindset in a design project, which is not just about "applying science" but also "doing science." Along with the verification efforts, faculty members tend to be more engaged with the capstone projects.

\subsection{Capstone Projects vs. Engineering Design Projects in Practice}

From the project management aspect, capstone projects are quite different from engineering design projects in practice. Listed below are some of the differences.

- A capstone project typically lasts for 8 months (September to April). Consider that students normally take five courses in a semester. The project effort is somehow equivalent to a full-time team working on the project for $8 / 5=1.6$ month (or roughly 6 weeks), which is a very short-term project in practice.

- If an engineering project cannot be completed before a deadline, it can be extended (maybe with some penalties). However, no matter how poorly the capstone projects may proceed, they must be concluded by the end of the semester (no extension essentially).

- In a company, it is common to have some kinds of hierarchy in a design team (e.g., a senior member leading a junior member). In a school environment, students may take different roles (e.g., design lead vs. management lead). However, they are not different in terms of ranks (e.g., one student should not "order" another student to do something).

- In an educational environment, we should focus more on the learning process than the quality of the final design. For example, if a team has their design fail in testing due to unexpected events but they have demonstrated a lot of learning experiences in the process, we can still give good grades to this team. In contrast, the quality of the final design is very important in an industrial environment.

In other words, capstone projects have their own features and limitations, which may not be recognized by other stakeholders (e.g., project sponsors). Accordingly, capstone instructors, based on their experience, should take more control to structure the capstone design process that fits for their students. Considerations include the proper design skills and tasks that should be learned at the level of the final-year engineering students. At the same time, we should empower our students to take control of their own projects (rather than controlled by other stakeholders) to practice independent and critical thinking. 


\section{PEDAGOGICAL APPROACHES}

Without highly structured contents such as DM to teach, we have tried various pedagogical approaches to help students engage in and learn from the capstone design process. This section will discuss some key approaches, along with their pros and cons in our observation.

\subsection{Lectures and Online Modules}

When we focused on teaching DM initially, we followed a typical pattern by having three 1-hour lectures per week. Table 2 shows a sample schedule of a semester. As indicated there, DM does offer many well-structured contents, which should be able to guide design activities. However, it turns out that lectures were poorly received by students (e.g., low attendance). To make the lectures more interesting, we have used TopHat (https://tophat.com) and design examples for more interactions. While we can address the attendance issue at a certain degree, it remains challenging for students to connect DM materials with their projects. Thus, we have dropped the lecture format in the recent year and develop the self-learning online modules as a replacement.

The online modules were developed using the software Articulate Storyline (https://articulate.com/360/storyline). We designed them as self-paced tutorials with some readings, interactive activities and multiple-choice questions. The primary contents of these modules cover the three-stage capstone design process, as outlined in Table 1, with the breakdown of 4 modules for conceptual design, 3 modules for design development, and 3 modules for design verification. We have an additional 5 modules for other topics such as safety, reliability and human factors, which have been easily mistaken in capstone projects. Moving from lectures to online modules, we have the following observations.

- Online modules are better than lectures in view of utilizing the time of instructors. By saving the lecture hours, instructors can have more bandwidth to consult individual projects.

- Arguably, engineering design can be learned better by hands-on experience and reflective thinking (than by conceptual understanding). In this context, lectures do not seem to have advantages over online modules.

- It is difficult to comment how well students use online modules. We find that many teams have only one or two students to go through the online modules. Our interpretation is that students likely take online modules as an "academic duty," which can be shared by team members. On the positive side, student teams can fairly demonstrate some basic understanding in their project execution such as analysis vs. decision problems and the need of design testing.
Table 2: Schedule of DM-focused lectures.

\begin{tabular}{|c|c|c|c|}
\hline & Lecture 1 & Lecture 2 & Lecture 3 \\
\hline Week 1 & Introduction & $\begin{array}{l}\text { Stakeholder } \\
\text { relations }\end{array}$ & $\begin{array}{l}\text { Engineering } \\
\text { design process }\end{array}$ \\
\hline Week 2 & $\begin{array}{l}\text { Problem } \\
\text { statement and } \\
\text { analysis }\end{array}$ & $\begin{array}{l}\text { Team } \\
\text { formation and } \\
\text { dynamics }\end{array}$ & $\begin{array}{l}\text { Project } \\
\text { management }\end{array}$ \\
\hline Week 3 & $\begin{array}{l}\text { Requirements, } \\
\text { objectives and } \\
\text { constraints }\end{array}$ & $\begin{array}{l}\text { Metrics, } \\
\text { pairwise } \\
\text { comparison }\end{array}$ & $\begin{array}{l}\text { Ranking of } \\
\text { design } \\
\text { objectives }\end{array}$ \\
\hline Week 4 & $\begin{array}{l}\text { Design } \\
\text { functions }\end{array}$ & $\begin{array}{l}\text { Functional } \\
\text { block diagram }\end{array}$ & $\begin{array}{l}\text { Specifications, } \\
\text { house of quality }\end{array}$ \\
\hline Week 5 & $\begin{array}{l}\text { Creativity, } \\
\text { mental blocks }\end{array}$ & $\begin{array}{l}\text { Morphological } \\
\text { chart }\end{array}$ & $\begin{array}{l}\text { Creative } \\
\text { method in team }\end{array}$ \\
\hline Week 6 & & $\begin{array}{l}\text { Concept } \\
\text { selection }\end{array}$ & $\begin{array}{l}\text { Decision } \\
\text { matrix }\end{array}$ \\
\hline Week 7 & $\begin{array}{l}\text { Pareto optimal } \\
\text { and design } \\
\text { trade-off }\end{array}$ & $\begin{array}{l}\text { Decision } \\
\text { making with } \\
\text { uncertainty }\end{array}$ & Sketching \\
\hline Week 8 & CAD drawings & $\begin{array}{l}\text { Dimensioning } \\
\text { and tolerance }\end{array}$ & $\begin{array}{l}\text { Schematics and } \\
\text { 3D modeling }\end{array}$ \\
\hline Week 9 & $\begin{array}{l}\text { Prototyping } \\
\text { and proofing }\end{array}$ & $\begin{array}{l}\text { Design and } \\
\text { materials }\end{array}$ & $\begin{array}{l}\text { Bill of } \\
\text { materials and } \\
\text { cost estimation }\end{array}$ \\
\hline Week 10 & & $\begin{array}{l}\text { Design for } \\
\text { production }\end{array}$ & Reliability \\
\hline Week 11 & Maintainability & Sustainability & $\begin{array}{l}\text { User-friendly } \\
\text { design }\end{array}$ \\
\hline Week 12 & Human errors & $\begin{array}{l}\text { Robustness, } \\
\text { signal-to-noise }\end{array}$ & $\begin{array}{l}\text { Design of } \\
\text { experiments }\end{array}$ \\
\hline Week 13 & $\begin{array}{l}\text { Cases of design } \\
\text { failures }\end{array}$ & $\begin{array}{l}\text { Ethics in } \\
\text { design }\end{array}$ & Review \\
\hline
\end{tabular}

\subsection{Design Labs and Project Progress Reviews}

When we noticed the deficiency of the pedagogy "DM + Lectures", our first major change was the adoption of Design Labs (DLs). The duration of a DL is 2 hours. We used the first 30 minutes to discuss a DM topic (e.g., customer requirements, design objectives and constraints). Then, we asked the teams to discuss some related questions specific to their projects (e.g., list and discuss top three customer requirements of your project; what are the main constraints that will dominate your final design). The teaching assistants (TAs) would check and discuss the answers of their teams before the students could sign off the DL session. The instructor was also there to answer questions from students.

While DLs allow more interactions for students to learn DM for their projects, our overall assessment remains that DL cannot be very effective to support capstone projects. Listed below are our observations.

- Many students perceived DLs as academic duties to go through, rather than an occasion to support their projects. As a result, some teams just answered the DL questions quickly and wanted to finish the session as soon as possible.

- TAs generally do not have the skills to challenge the superficial answers (note: design does not always have right or wrong answers) and engage deeper discussions. 
- Logistically, DL is not efficient. During the teams' discussion time, TAs and instructor were mostly free (for about 30 minutes). When teams finished their answers at around a similar time, they would be waiting for us to sign off the DL session. As a result, we could not spend too much time with each team (less than 10 minutes in many cases).

Due to the drawbacks of DLs, we have used project progress reviews (PPRs) to engage design discussions with individual teams. In each PPR, an instructor would meet a team for 30 minutes to discuss some pre-set questions (e.g., clarify the project's scope and the preliminary design idea) related to the project. Overall, PPRs can allow more engaging discussions with student teams than DLs.

From lectures to DLs and PPRs, we somewhat notice one pattern of learning; that is, students tend to learn better by taking feedback of their work than by following instructions. For example, we require that every design project must have some performance metrics to assess the merits of their own design objectively. In our instructions (e.g., online modules), we define the notion of performance metrics and provide various examples and multiple-choice questions for understanding. However, when coming to the PPR, probably no more than half of the teams can define their performance metrics (PMs) properly for their projects. Though the notion of PMs is not difficult in our view, students can have various cognitive and intellectual barriers to use them meaningfully in a project. This explains the value of PPRs, which can help design teams to correct some misconceptions earlier, rather than catching some major issues at the end of the semester. At the same time, we think PPRs are not more-the-better as students may find them tedious and miss the space for trying and reflecting. Currently, we set three PPRs in the Fall term (as we think the initial stage of the project is critical), and one PPR in the Winter term. However, we are actively considering possible improvements regarding the format and frequency of PPRs.

\subsection{Peer Evaluations and Individual Contribution Reports}

In our case, all capstone projects must involve teamwork, and team dynamics is an important factor toward the success of the projects. For example, one "slacker" can easily drag down the whole team, as other members can be easily upset by apparent unfairness. To support and assess team dynamics, we have used the peer evaluation tool developed by ITP Metrics (https://www.itpmetrics.com). The tool asks our students to evaluate their team members in five categories (e.g., communication and project commitment) in a five-point scale. Then, each student would receive feedback by the peer, and the final score will be part of the final grade. We arrange peer evaluations around two times in a semester for some formative and summative feedback (so that some students can adjust their behavior during the projects).
One benefit of peer evaluations is that individual behaviors can be assessed directly by those who are impacted most (i.e., the peer). Also, the management of this tool is quite straightforward, and instructors do not need to do any grading. One potential drawback is that students can (falsely) assess everyone perfect in a team. As we do not work directly with the team, it is difficult for us to doubt the scores of peer evaluations. In addition, some students indicate that they feel uncomfortable to assess their own peer (especially true when they still need to work with the same peer during the semesters). It may take a higher level of maturity to constructively comment on their colleagues and peers.

To complement the peer evaluations, we have implemented the so-called individual contribution reports (ICRs) to support team dynamics in the recent year. Here, we ask each student to complete an ICR at the end of each semester to report on their specific contributions to the project. To regulate the contents, we advise the class to reference the three-sage capstone process and relevant design tasks (i.e., Table 1) so that students can frame their own efforts in a design context. While the weights of contributions in different aspects can vary (e.g., one student can do more conceptual design and communication, while another can do more design details), every student must contribute something in engineering design (e.g., do not allow a student "just" doing the final report).

As ICR is only implemented in the recent year, we need more time to observe on its effectiveness. Initially, we find ICRs are quite positive in design learning. First, for those students who are engaged in their design projects, they are proud stating their contributions in ICRs, which do not take them a lot of time. Also, while industry emphasizes teamwork, work credits still go to individuals (e.g., to charge the working hours to the client). ICRs are aligned with this practice and can provide an aspect about how individual works are supportive to the whole project. In the end, ICRs can help students to reflect on their own project work and integrate such experience for professional development.

On the other side, the grading of ICRs can be challenging. Besides the merits of the contributions, can there be other aspects for grading ICRs (e.g., selfreflection)? The authenticity of the contributions can also be difficult to verify. Thus, we have been considering to integrate ICRs with peer evaluations in the future plan.

\subsection{Research Supervision for Design Projects?}

This sub-section is about the supervision structure of capstone projects. We have been managing a class of 120 150 students, with 21-28 teams. Originally, we have adopted a structure with one or two instructors to oversee the capstone course and multiple faculty members to supervise individual projects (likely, one professor takes 12 projects, responsible for providing guidance and 
grading). This original structure is quite similar to the structure of thesis supervision, which expects the domain experts to provide adequate knowledge and experience for students to complete the projects. For the clarity of the following discussion, we refer this structure to as "research supervision."

In our observation, research supervision can have some drawbacks in the context of capstone projects. First, the number of research supervisors is quite high (about 20), and instructors need to take certain efforts for coordination. Also, these research supervisors are quite independent in terms of project guidance, leading to inconsistent learning experiences of students. Further, they may not recognize the features and limitations of a capstone design process as discussed in Section 3. Accordingly, they may not be able to support the design teams effectively in this context (e.g., they may ask the teams to try different ideas and somehow procrastinate design testing).

In addition, the interactions between research supervisors and student teams are of note. On the one hand, if a research supervisor has a strong view on the direction of the project, a student team tends not to take the ownership of the project, hindering the critical and reflective thinking in the design process. On the other hand, if a research supervisor expects independence of the team, a student team often does not know how to engage this type of supervisor productively, leading to weak interactions between them. In the end, it is not obvious for research supervisors to keep the right balance between domination and independence for the benefits of students.

As a further consideration, why do we need a domain expert to supervise a capstone project? In fact, students can ask questions to any domain experts in a university, and they should not lack access to the right information. However, due to the specific features of capstone projects, students need guidance from those who are familiar with the capstone design process and its typical challenges. Such knowledge and skills may not be commonly shared by research supervisors, as their supervision experiences are more related to research in specific domains. After all, research projects are different from capstone design projects.

Due to the above arguments, we have reduced the dependency of research supervision in the capstone course. Instead, instructors take the supervision role, who act as project managers and check the projects mainly using project progress reviews (PPRs), reports and presentations. With this arrangement, we note that students tend to receive more similar learning experiences across different projects. At the same time, instructors encourage students to seek advice from domain experts and take control of their own projects. Logistically, this arrangement incurs more workloads for instructors (i.e., overseeing vs. supervising). At the same time, we have observed very positive interactions between research supervisors and capstone teams. Thus, we are not quite eliminating research supervisors and keep exploring the improvement of the supervision structure.

\section{CONCLUSIONS}

This paper has reported our five-year journey revising the capstone design course. One important realization is the limitations of design methodology (DM) in the teaching of capstone design. The stated concerns of DM include its context-free nature (e.g., independence of designers and design problems) and emphasis of deductive reasoning for problem solving. By not depending on DM, we adjust the capstone design process that is specific to the students' needs and the school's context. Instead of teaching "design methods," we characterize three stages of the capstone design process. Then, we explain typical design tasks associated with each stage and let students work on them. The learning experience mainly comes from our regular checkpoints and feedback on students' design tasks. Among different pedagogical approaches, we find project progress reviews (PPRs) and individual contribution reports (ICRs) are helpful to provide guidance for design teams and support positive team dynamics.

When we look back, the current shape of our capstone course is aligned with the topics of project-based learning and learning-by-doing [1], [2], [7], and [9]. With more studies of these topics, we plan to refine the online modules, integrate peer evaluations and individual contribution reports, and improve the format of project progress reviews and the supervision structure. Also, to better dissimilate our observations, we start to formalize some measures related to our capstone course such as:

- Individual quality measures of a project in conceptual design, design development and design verification

- Industry feedback of a project from the Design Fair

- Measure of team dynamics through peer evaluations. As one closing remark, we acknowledge the potential of teaching DM earlier to develop students' design skills progressively in the curriculum. To this aspect, our suggestion is to critically select DM tools for some lessopen design problems and carefully situate the learning environment for students. The goal here should not be just "knowing or executing" some DM tools, but also letting students appreciate how the systematic aspect of DM can practically help solving design problems.

\section{Acknowledgements}

This research is supported by the NSERC Chair in Design Engineering.

\section{References}

[1] Bell, S., 2010, "Project-Based Learning for the $21^{\text {st }}$ Century: Skills for the Future", The Clearing House, 83(2), pp. 39-43.

[2] Blumenfeld, P.C., Soloway, E., Marx, R.W., Krajcik, J.S., Guzdial, M. and Palincsar, A., 1991, "Motivating Project- 
Based Learning: Sustaining the Doing, Supporting the Learning”, Educational Psychologist, 26(3-4), pp. 369-398.

[3] Chakraharti A. and Blessing, L.T.M (ed.), 2014, An Anthology of Theories and Models of Design, Springer, London.

[4] Dieter, G.E. and Schmidt, L.C., 2013, Engineering Design, $5^{\text {th }}$ edition, McGraw Hill, New York.

[5] Dym, C.L., Little, P. and Orwin, E.J., 2014, Engineering Design: A Project-based Introduction, Wiley, New Jersey.

[6] Eggert, R.J., 2005, Engineering Design, Pearson, New Jersey.

[7] Mills J.E. and Treagust, D.F., 2003, "Engineering Education - Is Problem-Based or Project-Based Learning the Answer", Australasian Journal of Engineering Education, 3(2), pp. 216.
[8] Pahl, G. and Beitz, W., 1996, Engineering Design: A Systematic Approach, translated by Wallace, Blessing and Bauert, Springer, London.

[9] Roberts, J.W., 2012, Beyond Learning by Doing, Routledge, New York.

[10] Ullman, D.G., 2003, The Mechanical Design Process, $3^{\text {rd }}$ edition, McGraw-Hill, New York.

[11] Ulrich, K.T. and Eppinger, S.D., 2012, Product Design and Development, $5^{\text {th }}$ edition, McGraw Hill, New York.

[12] Wallance, K.M. and Blessing, L.T.M., 2000, "Observations on Some German Contributions to Engineering Design In Memory of Professor Wolfgang Beitz", Research in Engineering Design, 12, pp. 2-7. 